\title{
Protracted Bacterial Bronchitis, it is a Myth?
}

\author{
Ahmad Fadzil A. \\ Department of Paediatric, Kulliyyah of Medicine, IIUM Kuantan
}

\author{
Keywords \\ Chronic cough, wet and productive cough, \\ children, protracted bacterial bronchitis.

\section{Corresponding Author} \\ Associate Professor Dato' Dr. Ahmad \\ Fadzil Bin Abdullah \\ Department of Paediatric, Kulliyyah of \\ Medicine, IIUM, Kuantan, Pahang. \\ E-mail: drahmadfadzil@iium.edu.my \\ Received: 24 March 2021; Accepted: 11 \\ August 2021 \\ Doi: https://doi.org/10.31436/imjm.v20i4
}

\begin{abstract}
Protracted wet and productive chronic cough is a symptom that indicates there is an underlying cause and the possibility varies from simple to serious medical conditions. If the cough is accompanied by specific pointers in signs and symptoms, the diagnosis is apparent. Nevertheless, the challenge is to identify the diagnosis in children who cough without specific pointers. Recently, protracted bacterial bronchitis is one of the conditions that was proposed and postulated to conceive this clinical presentation. Since then, the understanding of Protracted Bacterial Bronchitis has escalated and deepened. However, there is still no unanimous consensus in definition, pathophysiology, diagnostic, treatment, long-term outcome, and even the entity itself. Further research is required to refine the understanding of this condition in several facets so that patients can be treated accordingly.
\end{abstract}

\section{INTRODUCTION}

Chronic cough is one of the common symptoms that bring the child to visit a health practitioner. When the chronic cough is associated with specific discernable signs and symptoms such as finger clubbing, chest deformity, weight loss, fever, and shortness of breath, the diagnosis can be unambiguous. Examples are asthma, gastroesophageal refluxes disease (GERD), bronchiectasis, bronchiolitis obliterans, cystic fibrosis, and pulmonary tuberculosis. Conversely, children may have chronic cough without any specific signs and symptoms. This will invoke a clinical conundrum in a fundamental issue like how significant is the cough or what is the underlying diagnosis. Protracted bacterial bronchitis (PBB) is one of the entities that has been proposed as one of the potential causes in children with chronic cough without any discernable signs and symptoms. The deliberation of PBB as an entity was only recently and there is still existing uncertainty regarding the pathophysiology, diagnostic, treatment, and long-term outcome.

\section{Chronic Bronchitis and Protracted Bacteria Bronchitis}

Children with protracted wet chronic cough without other discernable signs and symptoms have been recognised in clinical settings for quite some time. Many of these children were described as having chronic bronchitis (CB) in prior publications. The diagnostic criteria used by a majority of paediatricians in a survey to diagnose $\mathrm{CB}$ was recurrent wet cough for more than 2 weeks. Many of these children were treated with bronchodilators, antibiotics, and expectorants, and were believed to be asthmatic. ${ }^{1} \mathrm{~A}$ few years later, a group of children who were diagnosed with $\mathrm{CB}$ underwent a flexible bronchoscope of the airway with the proviso they have protracted wet cough and had not responded to bronchodilators. The gram stain of bronchoalveolar alveolar lavage (BAL) fluid showed persistent white blood cells whilst the airway biopsy demonstrated mononuclear cells infiltrate. ${ }^{2}$ The expression $\mathrm{CB}$ was used to describe these children until Marchant and her team in 2006 studied the etiology of chronic cough in 108 children who exhibited a persistent cough for more 
than 3 weeks. ${ }^{3}$ The team applied an adult-algorithm to investigate these children and the children were bronchoscopes for BAL fluid. Forty-three children $(39.8 \%)$ were diagnosed as having PBB based on high neutrophil count in their BAL fluid. Other diagnoses were asthma, gastroesophageal reflux, and upper airway cough syndrome (UACS). However, they concluded the adult algorithm is unsuitable for use in children with chronic cough. Children should have a specific algorithm for chronic cough. In 2008, Shields and her group published a guideline for the assessment of children with chronic cough for the British Thoracic Society. ${ }^{4}$ Chronic cough was defined as a persistent cough for more than 8 weeks. The group acknowledges that $\mathrm{PBB}$ is one of the plausible diagnoses for a persistent wet productive cough. PBB was categorised under chronic endobronchial infection together with cystic fibrosis, primary ciliary dyskinesia, and immunodeficiency disorder. The group recommended that before diagnosing any children with $\mathrm{PBB}$, other conditions should be excluded and all these children should have their sputum cultured. For children who are confirmed to have PBB, a trial of chest physiotherapy and a 4 to 6 weeks course of antibiotics could be initiated. They expressed concern regarding the use of the term $\mathrm{CB}$ that may not have merely missed asthmatic cases but also other more sinister underlying conditions. In their analyses, based on studies, ,2,3,5-10 there were credible pieces of evidence of the entity PBB as a distinct chronic endobronchial infection.

In 2016, a task force on behalf of the European Respiratory Society did a systematic review on PBB. In the systematic review, the task force posed a set of questionnaires designed to extract published works of literature on children who suffered persistent wet or productive cough for more than 4 weeks unrelated to underlying diseases and without any specific cough pointers. ${ }^{11}$ The essence of the questionnaires was; evidence of $\mathrm{PBB}$ in clinical studies and guidelines, symptoms used to diagnose, bacteria cultured from lower respiratory tract infection and the microbiome, the possible pathology and mechanism, treatments and the outcome, and any prophylaxis. They were able to identify only 40 relevant articles and out of these 3 were random clinical trials (RCTs) in the retrospective 31 years. The task force established that PBB as an entity has been described in both prospective and retrospective studies, and in 7 out of 8 guidelines (except Japanese guidelines for chronic cough in children). The main criterion was chronic wet or productive cough without specific pointed symptoms. Response to antibiotics was used in most guidelines as one of the diagnostic criteria of PBB. However, the length of the antibiotic courses varied between studies with prospective studies ranging between 10 days to 2 weeks, and retrospective studies ranged between 17 days to 8 weeks. Nevertheless, it sets a consensus to an agreed 4 weeks as an accepted duration of chronic cough in the clinical definition.

\section{Protracted Bacteria Bronchitis}

Anne Chang et al in 2016 put forward the diagnostic criteria of PBB for clinical practice. She categorised it as per the following; 1) Clinical PBB as continuous wet or productive cough for more than 4 weeks, absence of other symptoms and signs pointed to other diseases, and cough resolved after 2 weeks course of appropriate antibiotics, 2) Micro PBB as wet or productive cough for more than 4 weeks, positive culture of the respiratory pathogen from BAL (Bacteria culture $>10^{4} \mathrm{CFU} / \mathrm{ml}$ on BAL) obtained from flexible bronchoscopy, and cough resolved after 2 weeks course of appropriate antibiotics, 3) PBB extended which is either clinical PBB or micro $\mathrm{PBB}$ that need 4 weeks antibiotics for cough resolution and 4) Recurrent PBB (more than 3 episodes of PBB). ${ }^{12}$

The probable underlying mechanism of the PBB constituted the damage to the endobronchial, predominantly the mucociliary from various insults especially viral infection. The impaired mucociliary function leads to defective airway clearance and inflammation of the endobronchial. The proliferation of the bacteria unfolds and common microorganisms isolated either single or often more than one bacterium were non-typeable Haemophilus influenzae, Streptococcus pneumonia, Moraxella catarrhalis, and occasionally Staphylococcus aureus. The persistent and significant airway inflammation, with unremitting bacterial infection, generate biofilm that coats the airway surface, and hence the children manifest chronic wet and productive cough. ${ }^{13}$ 
Biofilm is a matrix secreted by the bacteria that enhances attachment, facilitates assess to the nutrient, and reduces penetration of the antibiotic, thus providing substantial protection against antibiotics and making the bacterial difficult to eradicate with standard length course of antibiotic. ${ }^{14}$ Biofilm slowed the replication of the bacteria and thus, the infection inclined to be chronic persistent instead of acute as in tracheitis or bronchitis.

Biofilm contributes to the majority of nosocomial infections and is frequently associated with the catheter or medical devices implanted in the body. It is an assemblage of microbial cells enclosed in a selfproduced matrix that is irreversibly associated with living or inert matter. ${ }^{15}$

The airway bronchoscopy revealed an inflamed endobronchial with increase bronchial secretion and the airway biopsy showed normal airway tissue or occasionally with neutrophil's infiltration. ${ }^{16,17}$

\section{The Pro and Con Discourse}

The debate on the entity PBB endured when Bidiwala et al published a discourse on the pro and con altercation. ${ }^{18}$ The pro viewpoint is that there are credible pieces of evidence of $\mathrm{PBB}$ as an entity. This will avert misdiagnosed asthma hence prevent excessive usage and inappropriately utilised of asthma medications especially steroids. In addition, medication to treat $\mathrm{PBB}$ is available namely prolonged use of antibiotics, and emerging pieces of evidence indicate PBB might be a precursor to a more severe condition; adequate treatment is crucial. ${ }^{19}$ Nonetheless, the con contended that the diagnosis was established after antibiotics treatment, and dependent on the duration of wet cough as it is not feasible to retrieved microbiology samples in all cases. Moreover, a proportion of children with acute cough attributed to common respiratory tract infections such as rhinitis, pharyngotonsillitis, bronchiolitis, croup, and pneumonia persist to cough beyond 4 weeks. ${ }^{20}$ For these children, treatment is unnecessary as it will resolve without intervention. Evidence of antibiotic treatment relied on a few RCTs. The consequence is excessive and unnecessary usage of antibiotics with its' unwelcome complications. This will compound the overuse of antibiotics in respiratory illness as at present, the respiratory condition is the major reason for antibiotic usage.

Andrew Bush in 2018 proposed that PBB should be a description instead of a diagnosis. ${ }^{21}$ He insisted though PBB reduce the inappropriate use of the steroid. However, to prescribe extended antibiotic usage, microbiology evidence that substantiates the cough was caused by bacteria, and objective confirmation on response to antibiotics is imperative. He also floated the term; simple PBB, extended $\mathrm{PBB}$, recurrent $\mathrm{PBB}$, and pre bronchiectasis $\mathrm{PBB}$, and mooted perhaps each is a different endotype with distinct pathophysiology. A group of pulmonologists in 2019 delves into the issues and remarked the predicament of devising a diagnosis primarily rely on the duration and quality of chronic cough which lacks specificity and has inherent limitations. ${ }^{22}$ The limitations are; many of the PBBs maybe just a prolonged acute cough post-acute respiratory illness (ARI) which resolved by itself; concordance between parents and doctors regarding cough quality (wet versus dry cough) is age-dependent, being better in children less than 2 years old; many children have a recurrent cough that parents coalesce as persistent especially in children who develop frequent recurrent ARI notably children in crowded facilities such as day-care centre; the local difference in referral pattern may result in selection bias for aetiology, and exclusion modalities of the other causes are not clearly defined. $^{22}$ They were convinced that the present definition criteria to diagnose PBB would contribute to over-diagnose and overuse of antibiotics.

The information on antibiotic treatment is limited and reliant on retrospectives and prospective studies, and a small number of RCTs. The most influential RCT was published by Marchant et al in 2012 when the team did a double-blind randomised clinical trial on a group of children with protracted productive wet chronic cough. These children were diagnosed with PBB, and 2-weeks of oral amoxicillin-clavulanate was administered to the treatment group. ${ }^{23}$ The study showed the treated children had a significant resolution of cough comparison to the placebo group (48\% vs $16 \%$, $\mathrm{p}=0.015)$. Despite that, there are some reservations pertaining to the study. Children included were those 
with 3-week cough, a small sample size, prior treatment was not described, $50 \%$ of children were still coughing, $25 \%$ of the placebo group the cough resolved, and most patients whom the cough was unresolved had morbidities. ${ }^{22}$ This suggests that some of the children may not need antibiotics whilst others perhaps acquired a longer length of antibiotic treatment. The other 2 RCTs were quite erstwhile RCT (David 1991 and Gottfarb 1994).24,25 Marchant et. al. inferred in a Cochrane Database Systematic Review based on the 2 RCTs, antibiotics are efficacious for children with chronic wet cough [total odd ratio 0.12 (CI 0.05 0.29)]. ${ }^{26}$ However, the sample size was small in both studies, the studies were based on nasopharyngeal culture, and patients' inclusion criteria and outcome of treatment are vague.

\section{Chronic Cough}

The real prevalence of chronic cough is unknown in large part due to it being unspecific and the absence of validated objective measurement. It is considerably influenced by parent's recalled memory and consensus between the parents and healthcare providers, the locality where the children are, and the expertise of the health care provider they pursue. However, some studies investigate the causes of chronic cough (Table 1). The finding may be skewed as it was performed at the tertiary centres. Nevertheless, these centres had the ability to do specialised investigations. The causes are varied depending on the ages of children, localities, and researcher groups.

\section{PBB vs UACS}

Upper airway cough syndrome (UACS) is one of the important causes of chronic cough in children and can easily be missed explicitly by those who are not in Otorhinolaryngology (ORL)/Ear Nose Throat (ENT) specialty. Children with UACS are numerous and frequently encountered at all levels of health care providers. Thus, it is very important to recognise the pertinent signs and symptoms of UACS. Features that mark the difference between chronic cough caused by UACS and PBB are; chronic cough due to UACS is usually a recurrent/dry cough, the children tend to attend day-care and having a recurrent URTI, runny nose, allergy shiner and nasal crease, nasal voice, stertor, history allergies, snoring and ENT/ORL examination revealed post nasal drip and cobblestone appearance. ${ }^{32}$ Whereas in PBB, cough is persistent with normal ORL/ ENT evaluation and responded to the antibiotic.

\section{PBB, is it a myth?}

There is accumulative clinical evidence that links PBB with a chronic productive or wet cough. Hitherto, clinical guidelines that include $\mathrm{PBB}$ as an entity to be diagnosed and treated already exist. Though PBB is a distinct clinical entity, the present criteria to diagnose to a significant extent contribute to overdiagnosis and unnecessary use of antibiotics. Furthermore, it is impractical to retrieve bronchial secretion in all patients because it could be quite invasive for children, albeit at

Table 1: Causes of chronic cough in children

\begin{tabular}{|c|c|c|c|c|c|c|c|c|c|c|}
\hline & $\begin{array}{c}\text { age } \\
\text { (yrs) }\end{array}$ & $\begin{array}{l}\text { PBB } \\
\%\end{array}$ & $\begin{array}{l}\mathrm{UAC} \\
\mathrm{S} \\
\% \\
\end{array}$ & $\begin{array}{l}\text { Asthma } \\
\%\end{array}$ & $\begin{array}{l}\text { Bronchiectasis } \\
\%\end{array}$ & $\begin{array}{l}\text { GER } \\
\mathrm{D} \\
\%\end{array}$ & $\begin{array}{l}\text { Habitual } \\
\% 1\end{array}$ & $\begin{array}{l}\text { Structural } \\
\text { Exp: } \\
\text { tracheomalacia }\end{array}$ & $\begin{array}{l}\text { Spontaneous } \\
\text { resolution } \\
\%\end{array}$ & $\begin{array}{l}\text { Others } \\
\%\end{array}$ \\
\hline $\begin{array}{l}\text { Marchant } \\
2006^{3}\end{array}$ & $\begin{array}{l}2.6 \\
\text { med }\end{array}$ & 40 & 3 & 3 & 6 & 3 & 1 & - & 22 & 21 \\
\hline $\begin{array}{l}\text { Asilsoy } \\
200827\end{array}$ & $\begin{array}{l}8.4 \\
\pm 2.1\end{array}$ & 23 & 20 & 25 & 5 & 5 & - & 4 & 6 & 3 \\
\hline $\begin{array}{l}\text { Koshoo } \\
200928\end{array}$ & $\begin{array}{l}7.8 \\
(5-12)\end{array}$ & $\begin{array}{l}\text { Not } \\
\text { includ } \\
\text { ed }\end{array}$ & 23 & 13 & - & 28 & 10 & - & - & 25 \\
\hline $\begin{array}{l}\text { Chang } \\
201229\end{array}$ & $\begin{array}{l}4.5 \\
\text { mean }\end{array}$ & 41 & 1.4 & 15.8 & 9 & 2.3 & 4.3 & 6.1 & 13.9 & 6.1 \\
\hline $\begin{array}{l}\text { Usta Guc } \\
20133^{30}\end{array}$ & $\begin{array}{l}8.42 \\
\pm 2.6\end{array}$ & 12.2 & 18.6 & 31.4 & 3.2 & - & 5.7 & - & - & 20.5 \\
\hline $\begin{array}{l}\text { Gedik } \\
2015^{31}\end{array}$ & $\begin{array}{l}5.4 \\
\pm 3.8\end{array}$ & 11.9 & 13.7 & 24.9 & 5 & 2.7 & 5.5 & 0.4 & 0.4 & 35.5 \\
\hline
\end{tabular}


the moment it is the only specific investigation either to correctly diagnose or evaluate the response of the treatment. Thus, other parameters with satisfactory sensitivity and specificity, and less invasive ought to be conceived. More RCTs are needed not only to widen the choices of antibiotics but more important to optimise the duration without increasing complications which among others causing resistant microbes. Finally, more data is required to resolve whether $\mathrm{PBB}$ is a homogeneity or heterogeneity condition.

\section{REFERENCES}

1. Taussig LM, Smith SM, Blumenfeld R. Chronic bronchitis in childhood: what is it? Pediatrics 1981; 67:1-5.

2. Smith TF, Ireland TA, Zaatari GS, Gay BB, Zwiren GT, Andrews HG. Characteristics of children with endoscopically proved chronic bronchitis. Am J Dis Child 1985;139:1039-44.

3. Marchant JM, Masters IB, Taylor SM, Cox NC, Seymour GJ, Chang AB. Evaluation and outcome of young children with chronic cough. Chest 2006;129:1132-41. doi: 10.1378/chest.129.5.1132

4. Shields MD, Bush A, Everard ML, McKenzie SA, Primhak R. British Thoracic Society Guidelines Recommendations for the assessment and management of cough in children. Thorax 2008;63:iii1-iii15.

5. Morgan WJ, Taussig LM. The chronic bronchitis complex in children. Pediatr Clin North Am 1984;31:851-64.

6. Field CE. Bronchiectasis in childhood: aetiology and pathogenesis including a survey of 272 cases of doubtful irreversible bronchiectasis. Pediatrics 1949;4:231-48.

7. Field CE. Bronchiectasis in childhood: prophylaxis, treatment and progress with a follow up study of 202 cases of established bronchiectasis. Pediatrics 1949;4:355- 72.

8. Dodge R, Burrows B, Lebowitz MD, et al. Antecedent features of children in whom asthma develops during the second decade of life. J Allergy Clin Immunnol 1993;92:744-9.

9. Boule M, Gaultier C, Tournier B, et al. Lung function in children with recurrent bronchitis. Respiration 1979;38:127-34.
10. Seear M, Wensley D. Chronic cough and wheeze in children: do they all have asthma? Eur Respir J 1997;10:342-5.

11. Kantar A, Chang AB, Shields MD, Marchant JM, Grimwood K, Grigg J, et al. ERS statement on protracted bacterial bronchitis in children. Eur Respir J 2017;24;50(2):1602139. doi: 10.1183/13993003.02139-2016

12. Chang AB, Upham JW, Masters IB, Redding GR, Gibson PG, Marchant JM, et al. Protracted bacterial bronchitis: the last decade and the road ahead. Pediatr Pulmonol 2016;51:225-42. doi: 10.1002/ppul.23351

13. Craven V, Everard ML. Protracted bacterial bronchitis: reinventing an old disease. Arch Dis Child 2013;98:72-76. doi:10.1136/archdischild2012-302760

14. Stewart PS. Mechanisms of antibiotic resistance in bacterial biofilms. Int J Med Microbiol. 2002;292 (2):107-13. doi: 10.1078/1438-4221-00196

15. Jamal M, Ahmad W, Andleeb S, Jalil F, Imran M, Nawaz MA, Hussain T, Ali M, Rafiq M, Kamil MA. Bacterial biofilm and associated infections. J Chin Med Assoc 2018;81:7-11. doi: 10.1016/ j.jcma.2017.07.012.

16. Narang R, Bakewell K, Peach J, et al. Bacterial distribution in the lungs of children with proctracted bacterial bronchitis. PloSOne 2014;9:e108523.10.1371/journal.pone. 0108523

17. Douros K, Kitsanta P, Mermiri D, Grammeniatis V, Kavantzas N, Everard M, Fretzayias A. Priftis K. Endobronchial biopsies in children with protracted bacterial bronchitis. Eur Respir J 2013;42: Suppl. 57, 5017.

18. Bidiwala A, Krilov LR, Pirzada M, Patel SJ. ProCon Debate: Protracted Bacterial Bronchitis as a Cause of Chronic Cough in Children. Pediatr Ann. 2015;44(8):329-36. doi: 10.3928/0090448120150812-11.

19. Chang AB, Redding GJ, Everard ML. State of the Art - chronic wet cough: protracted bronchitis, chronic suppurative lung disease and bronchiectasis. Pediatr Pulmonol 2008;43:519_ 31 doi: 10.1002/ppul.23351.

20. Thompson M, Vodicka TA, Blair PS, et al. Duration of symptoms of respiratory tract infections in children: systematic review. BMJ 
2013;347:f7027. doi: 10.1136/bmj.f7027

21. Bush A. Persistent bacterial bronchitis: time to venture beyond the umbrella. Front Pediatr 2017;5:264. doi: 10.3389/fped.2017.00264. eCollection 2017.

22. de Benedictis FM, Carloni I, Comberiati P, Shields MD, Bush A, Chang AB.

Wet cough and nasal symptoms in children: can we do better? Front Pediatr 2019;7:459. doi: 10.3389/fped.2019.00459. eCollection 2019.

23. Marchant JM, Masters IB, Champion A, Petsky HL, Chang AB. Randomised controlled trial of amoxycillin-clavulanate in children with chronic wet cough. Thorax 2012;67:689-93. doi.org/10.1136/thoraxjnl-2011-201506

24. Darelid J, Lofgren S, Malmvall BE. Erythromycin treatment is beneficial for longstanding Moraxella catarrhalis associated cough in children. Scand J Infect 1993;25:323-9

25. Gottfarb P, Brauner A. Children with persistent cough: outcome with treatment and role of Moraxella catarrhalis? Scand J Infect 1994;26:54551

26. Marchant JM, Morris P, Gaffney J, Chang AB. Antibiotics for prolonged moist cough in children. Cochrane Database Syst Rev 2005;(4):CD004822. doi: 10.1002/14651858.CD004822.pub2

27. Asilsoy S, Bayram E, Agin H, Apa H, Can D, Gulle S, et al. Evaluation of chronic cough in children. Chest. 2008;134:1122-8. doi:10.1378/ chest.08-0885

28. Khoshoo V, Edell D, Mohnot S, Haydel R, Jr, Saturno E, Kobernick A. Associated factors in children with chronic cough. Chest. 2009;136:8115. doi:10.1378/chest.09-0649

29. Chang AB, Robertson CF, Van Asperen PP, et al. A multicenter study on chronic cough in children: burden and etiologies based on a standardized management pathway. Chest 2012;142(4): 943-50. doi.org/10.1378/chest.11-2725

30. Usta Guc B, Asilsoy S, Durmaz C. The assessment and management of chronic cough in children according to the British Thoracic Society guidelines: descriptive, prospective, clinical trial. Clin Respir J 2014;8:330-7. doi:10.1111/crj.12076

31. Gedik AH, Cakir E, Torun E. et al. Evaluation of 563 children with chronic cough accompanied by a new clinical algorithm. Ital J Pediatr 2015;41:73. doi:10.1186/s13052-015-0180-0

32. Brietzke SE, Shin JJ, Choi S, Lee JT, Parikh SR, Pena M, et al. . Clinical consensus statement: pediatric chronic rhinosinusitis. Otolaryngol Head Neck Surg 2014;151:542-53. doi:10.1177/0194599814549302 